\title{
Editorial
}

\section{Adapt and Thrive}

When I initially thought about this special issue on the evolving role of academic librarians, the idea was to demonstrate how librarians are moving forward, as though towards an ultimate goal or higher understanding. I wanted to show that librarians are getting smarter, more in tune with their patrons and more adept at reaching for that pinnacle. On reflection, more than a year after the pandemic started, I am convinced that this evolution is not toward some grandiose end of universal enlightenment-but rather it is, as Darwin would have it, a response to the environment. Librarians have weathered the pandemic in much the same ways they have weathered the growth of the Internet (and the doomsayers that it would replace libraries), seasons of austerity and accountability in higher education and other forces, external and internal.

Now it is true that librarians are getting smarter and more skilled, but I would argue that the attributes that have seen them through, which are particularly evident and necessary during COVID, are flexibility (or adaptability, agility, etc) and patience. In my opinion, these aspects have been essential throughout my career and, particularly in the past year or so.

Note that I am emphasizing the librarian (rather than the library) as the one evolving. Organizations are both more and less than the sum of their parts - but courageous change and heroic efforts come from individuals - and their efforts should be acknowledged and celebrated. We talk about organizations being adept and agile-but really it is the people who are. It is the individuals who see opportunities to engage with their larger institutions, who identify pain points or gaps in institutional knowledge than they can work to fill, who take advantage of technologies to transform services to be wherever the patron is. Librarians are looking external to their organizations to meet college and university priorities, to engage in collaborations that support student success and collaborate with researchers to create new knowledge and transform the curriculum. It is librarians who help set the priorities and direction of the library-those on the front line working with students to empower them in their studies and help them succeed in their chosen path and with faculty to further discovery and innovation, those adopting and mediating new technologies to improve access, remove barriers and preserve knowledge and many others who are responsive to both the environment and to patrons needs.

I am very excited about the variety of projects and perspectives in this issue but I will confess that I keep getting sidetracked by issues and random thoughts as well as reflections about the evolution of my own career - which I am sure is pretty typical in terms of how many turns and changes have occurred over the years (although I will not say exactly how many years!).

It is in the nature of librarians to be agile and responsive-not just to the patrons they serve but to the climate of their institutions, new technologies, and priorities. Even with the recent changes that COVID has wrought, it just seems like par for the course after so many years of paradigm shifts and change management (and every time someone says "unprecedented" change, I just want to laugh).

Like many others, my position has changed, in substantial ways no less than 5 times (not including interim assignments and additional responsibilities that have been added on top) the infamous "other duties as assigned" that we all do. A colleague has even more variety and 
demonstrates a commitment to stepping up to fill a gap when the organization has a need. She has been at various times:

- Middle Eastern/Islamic Studies Reference Librarian

- Virtual Reference Administrator

- Coordinator of Monographic Acquisitions

- Interim Coordinator of Copy Cataloging Unit, Cataloging Maintenance Unit and Government Documents Cataloging

- Coordinator of Cataloging Record Support

- Director of Library Storage Facility

Now this is just an illustration-and I expect that many librarians' resumes look like this. In many cases, this kind of professional record demonstrates a breadth of experience and knowledge-one that may be essential for library leaders (and when one has to define a focus for such a record, the theme is usually "library management").

Many librarians' jobs are project-based. There was a book I read a while ago (and I have no doubt referenced it before) from ASTD (now the Association for Talent Development) called Consulting on the Inside. It really spoke to me because it seemed so much of my work was project- or initiative-based - much of it collaborating with those outside the library on activities that were not strictly library tasks but did bring my expertise to bear. This keeps things interesting and keeps you learning, but it is very difficult to describe a typical day. In such cases, the job responsibilities cannot be reduced to a standard position description. This opportunity to continuously learn and engage in new projects is what drew me to librarianship - but it can also lead to invisible workand to overwork. As professionals and/or faculty, librarians have some latitude to direct their work efforts. While our positions may scope WHAT we do, academic freedom (which may be a distant memory, if not a myth, in some organizations) allows us to determine HOW we do our work. The growing accountability in higher education seems to have contributed to a somewhat reductionist view of our work and how it is assessed - the "data-driven" movement begs for metrics that evaluate the quantity (and quality) of work in an effort to have an "objective" and unassailable standard that will allow for administrative decisions and comparison across positions and units.

This ability to adapt is what has and will continue to make libraries, and librarians, endure. The doomsaying (and many articles and commentaries) of the 2000s that the internet would make libraries obsolete continues even today - with non-librarian colleagues joking when they meet a librarian "Oh, they still have those?" (Unfortunately, I am not kidding.)

In response to this kind of jocular dismissal, Yes, we still have those-and libraries are critical to the success of students, the ongoing research of faculty, and the preservation of and access to information. Anyone who thinks they can overlook librarians may want to consult Michael Moore among others. ${ }^{1}$

June's special issue does an exceptional job of representing the ways in which librarians assert their expertise and engage with the changing environment while modelling professional values, excellence in service, intellectual humility, agility, and patience. The articles in this issue investigate the activities and efforts librarians - from area studies librarians and subject specialists to scholarly communications librarians to those dedicated to instruction and teaching. Their commitment is both enduring and inspiring.

\section{Notes}

1. Bonnie Swoger, "Famous people like libraries and librarians!" Scientific American, July 19, 2013, https:// blogs.scientificamerican.com/information-culture/famous-people-like-libraries-and-librarians/. 